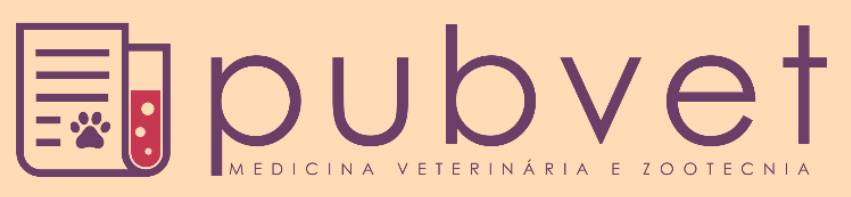

https://doi.org/10.31533/pubvet.v14n12a717.1-8

\title{
Prospecção de extratos vegetais como coadjuvantes de higiene bucal em cães raça Labrador Retriever
}

\author{
Thays de Carvalho Amorim Bolzan ${ }^{1} \bullet$, Juliana Aparecida Severi ${ }^{\circ}$, Janaina Cecília Oliveira \\ Villanova $^{2}{ }^{\circ}$, Dirlei Molinari Donatele ${ }^{3}$, Ana Paula Madureira ${ }^{\circ}$, Marcos Santos Zanini $^{2 * \bullet}$ \\ ${ }^{I}$ Mestranda do Programa de Programa de Pós- Graduação em Ciências Veterinárias do Centro de Ciências Agrárias e Engenharias da \\ Universidade Federal do Espírito Santo, Alegre - ES, Brasil \\ ${ }^{2}$ Docente do Programa de Programa de Pós- Graduação em Ciências Veterinárias do Centro de Ciências Agrárias e Engenharias da \\ Universidade Federal do Espírito Santo, Alegre - ES, Brasil \\ ${ }^{3}$ Docente, Universidade Federal do Espírito Santo, Departamento de Medicina Veterinária. Alegre - ES Brasil \\ ${ }^{4}$ Docente, Universidade Federal de São João del-Rei, Departamento Engenharia Biossistemas, São João del-Rei-MG Brasil \\ *Autor para correspondência, E-mail: marcos.zanini@ufes.br
}

\begin{abstract}
Resumo. O objetivo do presente estudo foi prospectar extratos vegetais como recurso terapêutico, frente à microbiota oral de cães. Para tal, foram obtidos extratos etanólicos de diferentes partes do Anacardium ocidentalis (cajueiro), Stryphnodendron adstringens (barbatimão), Punica granatum (romã), Uncaria tomentosa (unha de gato), Psidium guajava L.(goiaba), Momordica charantia L. (melão de São Caetano) e Harpagophytum procumbens (garra do diabo), preparados em diferentes concentrações. Microrganismos coletados da mucosa oral de 12 cães da raça Labrador, mantidos sob o mesmo manejo e alimentação, foram semeados em placas de petri com Agar BHI nas quais foram distribuídos circularmente discos de papel impregnados com $20 \mu \mathrm{L}$ de cada extrato em diferentes concentrações. Solução de digluconato de clorexidina a $0,12 \%$ em discos foi utilizada como controle positivo. Foram coletados três swabs de cada animal sendo então o experimento realizado em triplicata. As placas foram incubadas por 12 horas, a $36^{\circ} \mathrm{C}$. Os resultados das medidas dos halos de inibição foram submetidos à análise de variância de Kruskall-Wallis, seguida do teste de Dunn, com nível de significância de 5\%. Com base nos resultados os extratos de romã, goiaba e barbatimão foram selecionados, pois mostraram-se estatisticamente significativos nas concentrações $250 ; 125 ; 62,6 \mathrm{mg} / \mathrm{mL}$ o que sugere que os três extratos são candidatos potenciais para uso no desenvolvimento de produtos farmacêuticos para uso na higienização bucal dos cães.
\end{abstract}

Palavras-chave: Fitoterapia, odontologia veterinária, sensibilidade antimicrobiana

\section{Prospecting plant extracts as an adjuncts to oral hygiene in Labrador Retriever dogs}

Abstract. The present study aimed to prospect plant extracts as a therapeutic resource, compared to the oral microbiota of dogs. For this purpose, ethanol extracts from different parts of Anacardium Ocidentalis (cashew tree), Stryphnodendron adstringens (barbatimão), Punica granatum (pomegranate), Uncaria tomentosa (cat's claw), Psidium guajava L. (guava), Momordica charantia L. (melon from São Caetano) and Harpagophytum procumbens (devil's claw), prepared in different concentrations. Microorganisms collected from the oral mucosa of 12 Labrador dogs, maintained under the same management and feeding, were seeded in BHI Agar in a petri dish in which paper disks impregnated with $20 \mu \mathrm{L}$ of each extract were circulated. $0.12 \%$ chlorhexidine digluconate solution was used as a positive control. The plates were incubated for 12 hours at $36^{\circ} \mathrm{C}$. Three swabs were collected for each animal and each experiment was carried out 
in triplicate. The results of the inhibition halo measurements were subjected to the KruskallWallis analysis of variance, followed by the Dunn test, with a significance level of 5\%. Based on the results, pomegranate, guava, and barbatimão extracts were selected, as they were statistically significant at concentrations of $250 ; 125 ; 62,6 \mathrm{mg} / \mathrm{mL}$ which suggests that the three are potential candidates for use in the development of pharmaceutical products for use in oral hygiene of dogs.

Keywords: Veterinary dentistry, phytotherapy, antimicrobial sensitivity

\section{Prospección de extractos de plantas como complementos de la higiene bucal en perros Labrador Retriever}

Resumen. El objetivo del presente estudio fue buscar extractos de plantas como recurso terapéutico, contra la microbiota oral de los perros. Para ello, se obtuvieron extractos etanolicos de distintas partes de Anacardium Ocidentalis (anacardo), Stryphnodendron adstringens, Punica granatum (granada), Uncaria tomentosa (uña de gato), Psidium guajava L. (guayaba), Momordica charantia L. (melón de San Caetano) y Harpagophytum procumbens (garra del diablo), preparados en diferentes concentraciones. Los microorganismos recolectados de la mucosa oral de 12 perros labrador, mantenidos bajo el mismo manejo y alimentación, se sembraron en Agar BHI en una placa petri en la que se distribuyeron discos de papel impregnados con $20 \mu \mathrm{L}$ de cada extracto en diferentes concentraciones. Se utilizó una solución de digluconato de clorhexidina al $0,12 \%$ como control positivo. Se muestrearon tres hisopos de cada animal. Las placas se incubaron durante 12 horas a $36^{\circ} \mathrm{C}$. Los resultados de las medidas de los halos de inhibición se sometieron al análisis de varianza de Kruskall-Wallis, seguido de la prueba de Dunn, con un nivel de significancia del 5\%. Con base en los resultados, se seleccionaron extractos de granada, guayaba y $S$. adstringens, por ser estadísticamente significativos a las concentraciones $250 ; 125 ; 62,6 \mathrm{mg} / \mathrm{mL}$ lo que sugiere que los tres son candidatos potenciales para su uso en el desarrollo de productos farmacéuticos para uso en higiene bucal de los perros.

Palabras clave: Fitoterapia, odontología veterinaria, sensibilidad antimicrobiana

\section{Introdução}

O Brasil apresenta uma imensa biodiversidade com grande potencial para fitoterápicos. No entanto, faltam estudos que avaliem o uso de extratos vegetais para fins odontológicos, principalmente na área da medicina veterinária (Pereira et al., 2011). A partir de inúmeras espécies de plantas medicinais é possível obter compostos bioativos para uso em medicamentos e produtos de higiene e beleza (Ferreira et al., 2014; Hashemi et al., 2017). Diversos estudos relatam que as diferentes atividades farmacológicas apresentadas pelos extratos vegetais estão associadas aos compostos orgânicos provenientes do metabolismo primário ou secundário das plantas, tais como flavonoides, taninos, alcaloides, saponinas e terpenos (Kuete et al., 2006).

Biofilmes podem ser definidos como comunidades dinâmicas de células microbianas firmemente aderidas à superfície biótica e abiótica e embebidas numa matriz extracelular (Chenicheri et al., 2017). $\mathrm{Na}$ cavidade bucal, os biofilmes se formam inicialmente em superfícies como mucosa jugal e no esmalte dos dentes, sendo compostos predominantemente por microrganismos endógenos envoltos por proteínas e glicoproteínas presentes na saliva e no fluido gengival (Roudebush et al., 2005). A composição do biofilme é dinâmica, na medida em que outros componentes oriundos da alimentação e do hábito de roer são a ele incorporados. Assim, a progressão da formação do biofilme dentário induz diversas alterações no equilíbrio microbiano, podendo originar a placa dentária, formada por agregados de bactérias e seus subprodutos, componentes salivares, detritos orais e células epiteliais e inflamatórias ocasionais (Riggio et al., 2011; Whyte et al., 2014). A placa dentária, por sua vez, favorece o desenvolvimento da doença periodontal (PD), identificada como a ocorrência clínica mais comum em cães domésticos (Abdalla et al., 2017; Kyllar \& Witter, 2005). A formação do biofilme ocorre quase imediatamente após um procedimento profissional de limpeza dos dentes. Estudos demonstraram que em poucos minutos após o polimento, aproximadamente um milhão de microrganismos são depositados por $\mathrm{mm}^{2}$ na superfície 
do esmalte (Roudebush et al., 2005). Neste contexto, a profilaxia eficaz realizada pelo proprietário do animal no ambiente doméstico, como prática de home care, associada aos cuidados especializados em consultórios, constituem-se como procedimentos efetivos para o controle da PD impactando de forma favorável a saúde sistêmica e o bem-estar do animal (Bellows et al., 2019; Roudebush et al., 2005).

Os principais ingredientes ativos incorporadas nos produtos de higiene bucal de uso veterinário disponíveis comercialmente são a glicose oxidase, a lactoperoxidase, o gluconato de clorexidina (CG), o hexametafosfato de sódio (HMP) e os sais solúveis de zinco (ascorbato e gluconato) (Gallagher, 2013; Roudebush et al., 2005). Entre as formas farmacêuticas usualmente encontradas, as principais são as soluções para lavagem ou ingestão e, os cremes, as pastas, os géis e as espumas para escovação (Roudebush et al., 2005). Na atualidade, tem sido dada grande atenção para o uso de compostos bioativos naturais, em substituição aos ingredientes ativos sintéticos para a preparação de produtos de higiene e beleza de uso animal. Apesar do GC ser o composto de escolha para controle da placa dentária, o uso desta substância a longo prazo apresenta uma série de efeitos desagradáveis como a perda do paladar, pigmentação do esmalte, ardência e ulceração da mucosa bucal, o que torna sua aplicação periódica não recomendada (Pieri et al., 2010).

Neste contexto, justifica-se o interesse deste estudo de triagem na prospecção de extratos de plantas tradicionalmente empregadas na medicina popular para avaliação do potencial atividade frente a microrganismos da microbiota oral de cães da raça Labrador Retrivier. Foram eleitas as espécies Anacardium ocidentalis (caju), Stryphnodendron adstringens (barbatimão), Punica granatum (romã), Uncaria tomentosa (unha de gato), Psidium guajava L. (goiaba), Momordica charantia L. (melão de São Caetano) e Harpagophytum procumbens (garra do diabo), uma vez que há relatos na literatura acerca da atividade antimicrobiana para as mesmas.

\section{Material e métodos}

O material vegetal utilizado no presente trabalho foi selecionado a partir de um banco de plantas medicinais disponíveis no Laboratório de Produção Farmacêutica do CCENS-UFES. As espécies estudadas possuem registro no Herbário VIES - Subcuradoria Alegre/Jerônimo Monteiro da UFES e as espécies exóticas, que não dispõem de cultivo padronizado no Brasil foram obtidas junto a empresas especializadas do setor. A escolha foi feita com base na ação antimicrobiana relatada para cada extrato e na disponibilidade da substância vegetal. Foram preparados extratos etanólicos de cada parte das plantas estudadas, que foram posteriormente secos por liofilização. Na Tabela 1 são sumarizadas as informações acerca dos extratos.

Tabela 1. Identificação da planta, procedência, parte da planta e tipo de extrato empregado

\begin{tabular}{lccccc}
\hline Nome científico & Nome popular & Sigla & Procedência & Registro & Parte utilizada \\
\hline Anacardium ocidentalis & Cajueiro & CAO & Jerônimo Monteiro-ES & VIES30551 & Casca do caule \\
Harpagophytum procumbens & Garra do diabo & RHP & Massaro-SP & 7890529283225 & Raiz \\
Momordica charantia & Melão de São Caetano & MSC & Alegre-ES & VIES1086 & Folhas \\
Psidium guajava & Goiabeira & FPG & Jerônimo Monteiro-ES & VIES30552 & Folhas \\
Punica granatum & Romã & CPG & Alegre- ES & VIES34873 & Casca do fruto \\
Stryphnodendron adstringens & Barbatimão & CSA & Massaro-SP & 7898529281047 & Casca \\
Uncaria tomentosa & Unha de gato & CUT & Massaro-SP & 7898529282563 & Casca do caule \\
\hline
\end{tabular}

\section{Animais e comitê de ética}

Foram utilizados 12 animais da raça Labrador Retrivier, sendo sete fêmeas e cinco machos, com idade de um ano e peso médio de $28,0 \mathrm{~kg}$. A dieta oferecida foi a mesma para todos os animais estudados em um período de 90 dias que antecedeu a coleta e não foram realizados procedimentos preliminares de higienização bucal. Para cada animal foram coletadas três amostras da cavidade bucal, utilizando swabs estéreis. Ao coletar cada amostra oral, o coletor teve o cuidado de friccionar o swab contra os dentes e gengivas dos cães, simulando os movimentos de limpeza e remoção da placa. Em seguida, estes swabs foram armazenados em tubos estéreis e enviados para o laboratório para posteriores análises. $\mathrm{O}$ 
protocolo de estudo foi aprovado pelo Comitê de Ética em Pesquisa em Animais da Universidade Federal do Espírito Santo (CEUA 046/15).

\section{Avaliação in vitro da sensibilidade microbiana}

Para impregnação nos discos de papel filtro Whatman grau 1 estéreis, os extratos secos estudados foram previamente solubilizados em propilenoglicol, sendo obtidas soluções nas concentrações de 5; 31,$25 ; 62,5 ; 125$ e $250 \mathrm{mg} / \mathrm{mL}$. O experimento foi realizado em triplicata. Em cada placa foram incubados sete discos, entre os quais um disco impregnado com $20 \mu \mathrm{L}$ de solução de digluconato de clorexidina a $0,12 \%$ como controle positivo ou padrão ouro uma vez que este produto é a base da maioria dos antissépticos orais de uso humano. O diluente propileno glicol contendo $20 \mu \mathrm{L}$ no disco foi empregado como controle negativo. Os discos foram distribuídos sobre a superfície do meio de cultura sólido Brain Heart Infusion Agar (BHI), com modificações ao método de Kirby-Bauer (Bauer et al., 1966), previamente semeado com o inóculo bacteriano com auxílio de uma pinça estéril. As placas foram incubadas em estufa microbiológica a $37^{\circ} \mathrm{C}$ por 12 horas quando então os halos de inibição do crescimento em torno de cada amostra foram medidos.

Os resultados mais relevantes foram para romã, goiaba e barbatimão aos quais aplicaram-se as análises estatísticas utilizando-se o pacote estatístico (GraphPad Prism 6.0, Graph Prism Inc., San Diego, CA). Os testes, de normalidade de Shapiro-Wilk e de homocesdasticidade de Bartlett's, foram conduzidos para testar as hipóteses nulas de que os dados teriam sido amostrados, respectivamente, a partir de uma distribuição Gaussiana e que apresentariam homogeneidade de variâncias (Shapiro \& Wilk, 1965). Como dados se desviaram da distribuição gaussiana $(\mathrm{P}<0,05)$ e apresentaram heterocedasticidade $(\mathrm{P}<0,05)$, foram analisados pela análise de variância de Kruskall-Wallis, seguida pelo pós-teste de Dunn. Todos os testes foram realizados considerando um nível de significância de 0,05 .

\section{Resultados}

De acordo com os resultados obtidos na análise de compostos fenólicos totais (Tabela 2) podemos observar que a presença de fenólicos totais são fundamentais na ação antimicrobiana.

Tabela 2. Descrição dos metabólitos secundários presentes nas espécies vegetais estudadas

\begin{tabular}{|c|c|c|c|c|}
\hline \multirow[b]{2}{*}{ Nome popular } & \multirow[b]{2}{*}{ Sigla } & \multirow[b]{2}{*}{ Metabólitos secundários confirmados } & \multicolumn{2}{|c|}{ Fenóis totais } \\
\hline & & & $\% \mathrm{FT}$ & $\begin{array}{c}\text { gEAG/100g } \\
\text { Amostra }\end{array}$ \\
\hline Caju & $\mathrm{CAO}$ & Compostos fenólicos; Flavonoides; Taninos²; Terpenóides & 38,007 & 38,01 \\
\hline Garra do diabo & RHP & Compostos fenólicos; Flavonoides; Terpenóides & 8,544 & 8,54 \\
\hline Melão de São Caetano & MSC & Compostos fenólicos; Saponinas; Terpenóides & 3,190 & 3,19 \\
\hline Goiabeira & FPG & Compostos fenólicos; Flavonoides; Taninos ${ }^{1}$; Terpenóides & 20,443 & 20,44 \\
\hline Romã & CPG & Compostos fenólicos; Taninos ${ }^{1}$ & 56,496 & 56,50 \\
\hline Barbatimão & CSA & Compostos fenólicos; Flavonoides; Taninos²; Terpenóides & 43,060 & 43,06 \\
\hline Unha de gato & CUT & Compostos fenólicos; Alcaloides; Flavonoides; Terpenóides & 36,491 & 36,49 \\
\hline
\end{tabular}

CAO - Casca do cajueiro (Anacardium ocidentalis); CSA- casca do barbatimão (Stryphnodendronadstringens); CPG- casca do romã (Punica granatum) CUT - Casca de Unha de gato (Uncaria tomentosa); FAO - Folha do cajueiro (Anacardium ocidentalis); FPG - Folhas da goiabeira (Psidiumguajava L.); MSC- Folha do Melão de São Caetano (Momordica charantia L.); RHP - Raiz de Garra do diabo (Harpagophytum procumbens); ${ }^{1}$ Taninos hidrolisáveis, ${ }^{2}$ Taninos condensados. $* \% \mathrm{FT}=$ Porcentagem de teor de fenóis totais. ${ }^{*} \mathrm{gEAG} / 100 \mathrm{~g}$ Amostra = Equivalente de ácido gálico por 100g da amostra testada.

Após realização dos experimentos, observou-se a existência de zonas de inibição para todos os extratos testados, havendo, entretanto, diferenças entre as concentrações nas quais ocorreu a inibição do crescimento para cada concentração estudada. Os valores das zonas de inibição obtidos para todos os extratos, nas concentrações estudadas, são descritos na Tabela 3. Vale destacar ainda que os microrganismos foram suscetíveis também à presença da solução de digluconato de clorexidina $0,12 \%$ com halo de inibição (média: 5,08 mm) utilizada como controle positivo, confirmando tanto a existência de sensibilidade dos microrganismos bem como a existência de atividade antisséptica para os extratos estudados. Para eliminar a possibilidade de influência do diluente nos resultados, o propileno glicol puro foi estudado e não foi observada atividade para este frente à microbiota oral. 
Nenhuma diferença foi encontrada entre nas concentrações $5 ; 31,25$ e $62.5 \mathrm{mg} / \mathrm{mL}$ para os extratos Anacardium ocidentalis (caju), Uncaria tomentosa (unha de gato). Para Momordica charantia L. (melão de São Caetano) e Harpagophytum procumbens (garra do diabo) não foram observados diferença em nenhuma concentração. Uma vez que os maiores valores de halos de inibição foram observados para os extratos de Punica granatum (romã), Psidium guajava (goiaba) e Stryphnodendron adstringens (barbatimão), os resultados obtidos para estes foram então submetidos à análise estatística para avaliação da existência de diferença significativa entre as concentrações estudadas para cada extrato, a fim de definir a menor concentração a ser utilizada de cada um. Pode-se verificar a sensibilidade frente à microbiota oral nas concentrações $5 ; 31,25 ; 62,5 ; 125$ e $250 \mathrm{mg} / \mathrm{mL}$, de acordo com os gráficos abaixo.

Tabela 3. Valores médios das zonas de inibição $(\mathrm{mm})$ obtidas para todos os extratos nas diferentes concentrações

\begin{tabular}{|c|c|c|c|c|c|}
\hline \multirow[t]{2}{*}{ Extrato } & \multicolumn{5}{|c|}{ Halos de inibição $(\mathrm{mm})$ para cada concentração estudada $(\mathrm{mg} / \mathrm{mL})$} \\
\hline & 5,0 & 31,25 & 62,5 & 125,0 & 250,0 \\
\hline Caju & $1 \mathrm{~mm}$ & $2,25 \mathrm{~mm}$ & $3,08 \mathrm{~mm}$ & $3,5 \mathrm{~mm}$ & $4,8 \mathrm{~mm}$ \\
\hline Romã & $3,50 \mathrm{~mm}$ & $5,16 \mathrm{~mm}$ & $6,08 \mathrm{~mm}$ & $7,16 \mathrm{~mm}$ & $8,25 \mathrm{~mm}$ \\
\hline Goiaba & $2,58 \mathrm{~mm}$ & $3,83 \mathrm{~mm}$ & $5 \mathrm{~mm}$ & $6,41 \mathrm{~mm}$ & $8 \mathrm{~mm}$ \\
\hline Barbatimão & $3 \mathrm{~mm}$ & $3,91 \mathrm{~mm}$ & $5 \mathrm{~mm}$ & $5,91 \mathrm{~mm}$ & $6,75 \mathrm{~mm}$ \\
\hline Unha de gato & $1,16 \mathrm{~mm}$ & $2,75 \mathrm{~mm}$ & $3,58 \mathrm{~mm}$ & $4,16 \mathrm{~mm}$ & $5,33 \mathrm{~mm}$ \\
\hline Garra do diabo & $0 \mathrm{~mm}$ & $0,83 \mathrm{~mm}$ & $1,58 \mathrm{~mm}$ & $2,5 \mathrm{~mm}$ & $3,41 \mathrm{~mm}$ \\
\hline Melão de São Caetano & $1,66 \mathrm{~mm}$ & $2,58 \mathrm{~mm}$ & $2,91 \mathrm{~mm}$ & $3,58 \mathrm{~mm}$ & $4,6 \mathrm{~mm}$ \\
\hline
\end{tabular}

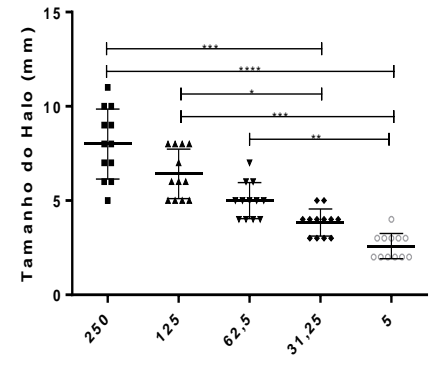

Concentração de Folhas de Psidium guajava (mg)

Gráfico 1. Tamanho do halo (mm) medidos em diferentes concentrações (mg) de Psidium guajava. Diferenças estatísticas avaliadas mediante ANOVA de Kruskall-Wallis seguida de pósteste de Dunn. A presença dos asteriscos mostra onde se encontram as diferenças significativas com $\mathrm{P}<0,05(*), \mathrm{P}<$ $0,01(* *), \mathrm{P}<0,001(* * *) \mathrm{P}<$ $0,0001(* * * *)$.

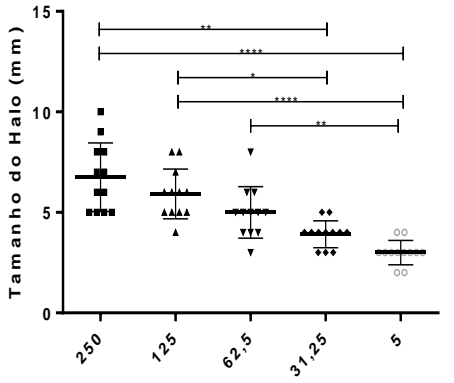

Concentração de Stryphnodendron adstringens $(\mathrm{mg})$

Gráfico 2. Tamanho do halo (mm) medidos em diferentes concentrações (mg) de Stryphnodendron adstringens. Diferenças estatísticas avaliadas mediante ANOVA de Kruskall-Wallis seguida de pós-teste de Dunn. A presença dos asteriscos mostra onde se encontram as diferenças significativas com $\mathrm{P}<0,05$ (*), $\mathrm{P}<0,01(* *), \mathrm{P}<0,001(* * *), \mathrm{P}$ $<0,0001(* * * *)$.

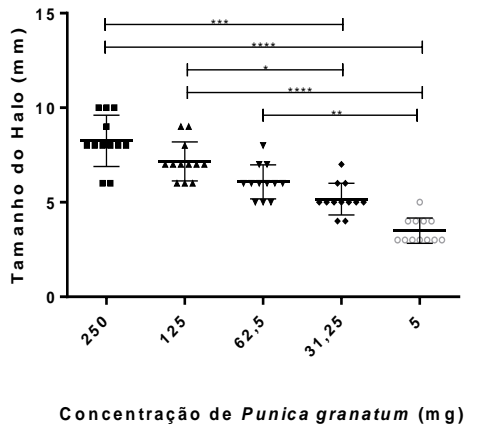

Gráfico 3. Tamanho do halo (mm) medidos em diferentes concentrações (mg) de Punica granatum. Diferenças estatísticas avaliadas mediante ANOVA de Kruskall-Wallis seguida de pós-teste de Dunn. A presença dos asteriscos mostra onde se encontram as diferenças significativas com $\mathrm{P}<$ 0,05 (*), $\mathrm{P}<0,01$ (**), $\mathrm{P}<0,001$ $(* * *), \mathrm{P}<0,0001(* * * *)$.

\section{Discussão}

Este estudo foi pioneiro em usar os extratos selecionados frente à microbiota oral de cães da raça Labrador, visando o desenvolvimento de novos produtos com propriedades antimicrobianas, uma vez que há uma nova tendência em cuidados a saúde oral dos animais de estimação, e produtos odontológicos veterinários estão sendo comercializados nesta linha.

Para todos os extratos descritos e estudados foram confirmadas a presença de compostos fenólicos o que justifica o fato da formação de halos de inibição em todas as placas incubadas, comprovando a existência da sensibilidade dos microrganismos presentes nas microbiotas pesquisadas frente aos extratos sendo a romã o extrato com maior \%FT e maior efetividade frente à microbiota oral dos cães estudados. Vale destacar ainda que os microrganismos foram suscetíveis também à presença da solução 
de digluconato de clorexidina utilizada como controle positivo, confirmando tanto a existência de sensibilidade dos microrganismos bem como a existência de atividade antisséptica para os extratos.

Quando da análise dos resultados, pode-se observar que para o extrato das cascas do cajueiro e das raízes de garra do diabo, não houve inibição do crescimento para todas as concentrações estudadas, sendo que para o primeiro, as zonas de inibição efetivas foram observadas somente para as concentrações de 125,0 e 250,0 $\mathrm{mg} / \mathrm{mL}$. Uma vez que para o desenvolvimento de produtos farmacêuticos recomenda-se as menores concentrações possíveis de extrato, para que o custo das formulações seja reduzido e não haja interferência nas propriedades dos produtos acabados, ambos os extratos da garra do diabo e do cajueiro foram excluídos do estudo. Ainda, a partir dos resultados pode-se inferir que com o aumento da concentração foi observado o aumento da zona de inibição, para todos os extratos estudados, o que permite concluir que todos foram mais ativos nas maiores concentrações testadas.

Os extratos de Punica granatum (romã); Psidium guajava L. (goiaba) e Stryphnodendron adstringens (barbatimão), apresentaram maiores halos de inibição comparado aos demais extratos do presente estudo, demonstrando aumento da atividade do extrato em função do aumento da concentração. Observa-se nos gráficos 1,2 e 3 que quanto maior a concentração dos compostos testados maiores foram os halos de inibição de crescimento dos microrganismos. Os mesmos demostram que as concentrações de 250,125 e $62,5 \mathrm{mg}$ foram de eficácias significativas. Sendo que as concentrações de 250 e $125 \mathrm{mg}$ apresentaram diferenças $(\mathrm{P}<0,05)$ com relação aquelas de 31,25 e $5 \mathrm{mg}$ enquanto que concentração de $62,5 \mathrm{mg}$ mostrou-se estatisticamente diferente daquela de $5 \mathrm{mg}$. Assim, conclui-se que as concentrações de 250 e $125 \mathrm{mg}$ foram as mais efetivas para todos os compostos.

Para os diferentes extratos obtidos a partir das cascas do Punica granatum (romã) é relatada a presença de taninos hidrolisáveis, elagitaninos e ácido elágico, além de antocianinas e flavonoides (Singh et al., 2009; Wang et al., 2018). Assim, como no presente estudo onde observa-se a presença de taninos hidrolisáveis e 56,5\% de compostos fenólicos totais. Tais achados corroboram com Moorthy et al. (2013), onde observaram que os taninos são os principais responsáveis pela atividade antimicrobiana dos extratos de romã, uma vez que possui a capacidade de se complexar com proteínas e inativar enzimas dos microrganismos, o que justifica a sensibilidade da microbiota oral frente ao extrato de romã do presente estudo. $\mathrm{O}$ extrato de romã apresentou a melhor suscetibilidade frente à microbiota oral na concentração de $250 \mathrm{mg}$ e foi evidenciado declínio relativo nas menores concentrações estudadas. Esses resultados corroboram também com um estudo feito por Pereira et al. (2006) que observaram atividade antimicrobiana in vitro do extrato hidroalcóolico da casca do fruto da romã frente a linhagens comuns ao biofilme supra gengival humano: Streptococcus mitis, Streptococcus mutans, Streptococcus sanguis, Streptococcus sobrinus e Lactobacillus casei.

Segundo Rahman et al. (2014) o extrato de folhas de Psidium guajava (goiaba) contém compostos flavonóides que atuam como antimicrobianos, eles também observaram a presença de quatro principiais componentes antimicrobianos incluindo esqualeno, fitol, biciclo e azuleno. Igualmente, no presente estudo observa-se a presença de compostos fenólicos, flavanóides, taninos hidrolisáveis e terpenóides. Patel et al. (2019) validam o uso do extrato obtido das folhas da goiabeira na concentração de $50 \mu \mathrm{g} / \mathrm{mL}$ para uso medicinal devido à capacidade do extrato de interferir no sistema "quorum sensing" bacteriano de Staphylococcus aureus, Chromobacterium violaceum, Serratia marcescens, Pseudomonas aeruginosa e Streptococcus pyogenes de forma semelhante a achados relatados no atual experimento.

Quanto ao Stryphnodendron adstringens (barbatimão), os principais atributos característicos farmacológicos encontrados na literatura são como adstringente, anti-inflamatório e antimicrobiano das cascas (Ishida et al., 2006; Souza et al., 2007). A casca do caule é a principal parte utilizada na preparação de extratos. Os extratos são ricos em compostos fenólicos, taninos e flavonoides (Santos et al., 2002). Substâncias estas também encontradas no presente estudo onde observou-se a presença de compostos fenólicos, flavonoides, taninos condensados e terpenóides e sensibilidade aos microrganismos testados nas concentrações de $250,125,62.6,31.25$ e $5 \mathrm{mg} / \mathrm{mL}$.

\section{Conclusão}

Assim, neste experimento foi observado efeito de suscetibilidade frente à microbiota natural de cães labradores dos extratos de romã, goiaba e barbatimão. O uso desses extratos pode ser considerado métodos adjuvantes da profilaxia e tratamento de afecções da cavidade oral. 


\section{Referências bibliográficas}

Abdalla, S. L., Costa, S. S., Gioso, M. A., Casanova, L. M., Coutinho, M. A. S., Silva, M. F. A., Botelho, M. C. da S. N., \& Dias, R. S. G. (2017). Efficacy of a Kalanchoe gastonis-bonnieri extract to control bacterial biofilms and dental calculus in dogs. Pesquisa Veterinária Brasileira, 37(8), 859-865. DOI: https://doi.org/10.1590/s0100-736x2017000800013

Bauer, A. W., Kirby, W. M. M., Sherris, J. C., \& Turck, M. (1966). Antibiotic susceptibility testing by a standardized single disk method. American Journal of Clinical Pathology, 45(4), 493. DOI: https://doi.org/10.1093/ajcp/45.4_ts.493

Bellows, J., Berg, M. L., Dennis, S., Harvey, R., Lobprise, H. B., Snyder, C. J., Stone, A. E. S., \& Van de Wetering, A. G. (2019). 2019 AAHA dental care guidelines for dogs and cats. Journal of the American Animal Hospital Association, 55(2), 49-69. DOI: https://doi.org/10.5326/JAAHA-MS$\underline{6933}$

Chenicheri, S., Usha, R., Ramachandran, R., Thomas, V., \& Wood, A. (2017). Insight into oral biofilm: primary, secondary and residual caries and phyto-challenged solutions. The Open Dentistry Journal, 11, 312. DOI: https://doi.org/10.2174/1874210601711010312

Ferreira, T. S., Moreira, C. Z., Cária, N. Z., Victoriano, G., Silva Jr, W. F., \& Magalhães, J. C. (2014). Phytotherapy: an introduction to its history, use and application. Revista Brasileira de Plantas Medicinais, 16(2), 290-298. DOI: https://doi.org/10.1590/s1516-05722014000200019

Gallagher, L. (2013). The effect of dental products and natural chews on canine oral bacteria. Letters in General Microbiology, 1(2), 1-4.

Hashemi, M., Ramezani, V., Seyedabadi, M., Ranjbar, A. M., Jafari, H., Honarvar, M., \& Fanaei, H. (2017). Formulation and optimization of oral mucoadhesive patches of myrtus communis by box behnken design. Advanced Pharmaceutical Bulletin, 7(3), 441. DOI: https://doi.org/10.15171/apb.2017.053

Ishida, K., de Mello, J. C. P., Cortez, D. A. G., Filho, B. P. D., Ueda-Nakamura, T., \& Nakamura, C. V. (2006). Influence of tannins from Stryphnodendron adstringens on growth and virulence factors of Candida albicans. Journal of Antimicrobial Chemotherapy, 58(5), 942-949. DOI: https://doi.org/10.1093/jac/dkl377

Kuete, V., Tangmouo, J. G., Beng, V. P., Ngounou, F. N., \& Lontsi, D. (2006). Antimicrobial activity of the methanolic extract from the stem bark of Tridesmostemon omphalocarpoides (Sapotaceae). Journal of Ethnopharmacology, 104(1-2), 5-11. DOI: https://doi.org/10.1016/j.jep.2005.08.002

Kyllar, M., \& Witter, K. (2005). Prevalence of dental disorders in pet dogs. Veterinarni Medicina, 50(11), 496-515. DOI: https://doi.org/10.17221/5654-vetmed

Moorthy, K., Punitha, T., Vinodhini, R., Sureshkumar, B. T., Vijayalakshmi, P., \& Thajuddin, N. (2013). Antimicrobial activity and qualitative phytochemical analysis of Punica granatum Linn. (PERICARP). Journal of Medicinal Plants Research, 7(9), 474-479. DOI: https://doi.org/10.5897/JMPR12.953

Patel, P., Joshi, C., Birdi, T., \& Kothari, V. (2019). Anti-infective efficacy of Psidium guajava L. leaves against certain pathogenic bacteria. F1000Research, 8(12). DOI: https://doi.org/10.12688/f1000research.17500.2

Pereira, E. M., Gomes, R. T., Freire, N. R., Aguiar, E. G., Brandão, M. G. L., \& Santos, V. R. (2011). In vitro antimicrobial activity of Brazilian medicinal plant extracts against pathogenic microorganisms of interest to dentistry. Planta Medica-Natural Products and MedicinalPlant Research, 77(4), 401-404. DOI: https://doi.org/10.1055/s-0030-1250354

Pereira, J. V, Pereira, M. S. V., Sampaio, F. C., Sampaio, M. C. C., Alves, P. M., Araújo, C. R., \& Higino, J. S. (2006). Efeito antibacteriano e antiaderente in vitro do extrato da Punica granatum Linn. sobre microrganismos do biofilme dental. Revista Brasileira de Farmacognosia, 16(1), 88-93. DOI: https://doi.org/10.1590/S0102-695X2006000100016

Pieri, F. A., Mussi, M. C., Fiorini, J. E., \& Schneedorf, J. M. (2010). Efeitos clínicos e microbiológicos do óleo de copaíba (Copaifera officinalis) sobre bactérias formadoras de placa dental em cães. Arquivo Brasileiro de Medicina Veterinária e Zootecnia, 62(3), 578-585. DOI: 


\section{https://doi.org/10.1590/S0102-09352010000300012}

Rahman, M. M., Ahmad, S. H., Mohamed, M. T. M., \& Ab Rahman, M. Z. (2014). Antimicrobial compounds from leaf extracts of Jatropha curcas, Psidium guajava, and Andrographis paniculata. The Scientific World Journal, 2014(635240), 1-9. DOI: https://doi.org/10.1155/2014/635240

Riggio, M. P., Lennon, A., Taylor, D. J., \& Bennett, D. (2011). Molecular identification of bacteria associated with canine periodontal disease. Veterinary Microbiology, 150(3-4), 394-400. DOI: https://doi.org/10.1016/j.vetmic.2011.03.001

Roudebush, P., Logan, E., \& Hale, F. A. (2005). Evidence-based veterinary dentistry: a systematic review of homecare for prevention of periodontal disease in dogs and cats. Journal of Veterinary Dentistry, 22(1), 6-15. DOI: https://doi.org/10.1177/089875640502200101

Santos, S. C., Costa, W. F., Ribeiro, J. P., Guimarães, D. O., Ferri, P. H., Ferreira, H. D., \& Seraphin, J. C. (2002). Tannin composition of barbatimão species. Fitoterapia, 73(4), 292-299. DOI: https://doi.org/10.1016/S0367-326X(02)00081-3

Shapiro, S. S., \& Wilk, M. B. (1965). An analysis of variance test for normality (complete samples). Biometrika, 52(3/4), 591-611. DOI: https://doi.org/10.2307/2333709

Singh, K., Jaggi, A. S., \& Singh, N. (2009). Exploring the ameliorative potential of Punica granatum in dextran sulfate sodium induced ulcerative colitis in mice. Phytotherapy Research, 23(11), 15651574. DOI: https://doi.org/10.1002/ptr.2822

Souza, T. M., Moreira, R. R. D., Pietro, R. C. L. R., \& Isaac, V. L. B. (2007). Avaliação da atividade anti-séptica de extrato seco de Stryphnodendron adstringens (Mart.) Coville e de preparação cosmética contendo este extrato. Revista Brasileira de Farmacognosia, 17(1), 71-75. DOI: https://doi.org/10.1590/s0102-695x2007000100015

Wang, D., Özen, C., Abu-Reidah, I. M., Chigurupati, S., Patra, J. K., Horbanczuk, J. O., Jóźwik, A., Tzvetkov, N. T., Uhrin, P., \& Atanasov, A. G. (2018). Vasculoprotective effects of pomegranate (Punica granatum L.). Frontiers in Pharmacology, 9, $544 . \quad$ DOI: https://doi.org/10.3389/fphar.2018.00544

Whyte, A., Bonastre, C., Monteagudo, L. V, Les, F., Obon, J., Whyte, J., \& Tejedor, M. T. (2014). Canine stage 1 periodontal disease: a latent pathology. The Veterinary Journal, 201(1), 118-120. DOI: https://doi.org/10.1016/j.tvj1.2014.05.005

Histórico do artigo:

Recebido: 20 de agosto, 2020.

Aprovado: 25 de setembro, 2020.

Disponível online: 5 de novembro, 2020.
Licenciamento: Este artigoé publicado na modalidade Acesso Aberto sob a licença Creative Commons Atribuição 4.0 (CC-BY 4.0), a qual permite uso irrestrito, distribuição, reprodução em qualquer meio, desde que o autor e a fonte sejam devidamente creditados. 